\title{
The Effect of Combustion Knock on the Instantaneous Heat Flux in Spark Ignition Engines
}

\author{
Johannes Mutzke, Blane Scott, Richard Stone; Department of Engineering Science, University of \\ Oxford
}

John Williams; BP Technology Centre, Pangbourne, UK

\begin{abstract}
Knocking combustion places a major limit on the performance and efficiency of spark ignition engines. Spontaneous ignition of the unburned air-fuel mixture ahead of the flame front leads to a rapid release of energy, which produces pressure waves that cause the engine structure to vibrate at its natural frequencies and produce an audible 'pinging' sound. In extreme cases of knock, increased temperatures and pressures in the cylinder can cause severe engine damage.
\end{abstract}

Damage is thought to be caused by thermal strain effects that are directly related to the heat flux. Since it will be the maximum values that are potentially the most damaging, then the heat flux needs to be measured on a cycle-bycycle basis. Previous work has correlated heat flux with the pressure fluctuations on an average basis, but the work here shows a correlation on a cycle-by-cycle basis.

The in-cylinder pressure and surface temperature were measured using a pressure transducer and eroding-type thermocouple. These sensors were installed side-by-side at the surface of the cylinder in order to investigate the relationship between knock and heat flux on a cycle-by-cycle basis. A finite difference method was implemented to solve the one-dimensional unsteady heat conduction equation and calculate the temperature distribution away from the surface of the combustion chamber, and thus the instantaneous heat flux. The knock intensity was varied by controlling the fuel quality, compression ratio, ignition timing and air-fuel ratio. The measured heat flux was compared with pressure-based knock indices and it was found that as knock intensity increases, the correlation with peak heat flux became stronger. Results from different fuels and engine operating conditions did not collapse onto the same trend line. At higher speeds and higher compression ratios the heat flux was higher at a given level of knock intensity. The co-location of the pressure transducer and heat flux sensor meant that a correlation was found on a cycle-by-cycle basis.

\section{Introduction}

The development of the spark ignition (SI) engine has been at the forefront of the automotive industry since the late 19th century. It still remains the most popular choice of powertrain for private passenger vehicles worldwide, with almost $100 \%$ of newly purchased cars in China powered by an SI engine according to research undertaken by Bosch [1]. Although there have been improvements in terms of range and charge times of electric vehicles, the high expense of batteries and lack of charging infrastructure make them less attractive to consumers and this situation will remain for the foreseeable future. Spark ignition engines are a cost-effective and convenient choice for consumers, and this is why companies in the automotive industry continue to invest in improving the performance and efficiency of internal combustion engines

In recent years, due to increasing environmental awareness and more stringent regulations, car manufacturers have been forced to investigate more advanced systems to reduce fuel consumption and emissions. These include technologies such as direct fuel injection, variable valve timing and engine downsizing, with the use of supercharging. Downsizing allows smaller engines to produce a similar power output in comparison to a larger, naturally aspirated engine and yet have a greater thermal efficiency, reducing fuel consumption and emissions. However, in such engines there is a greater likelihood that combustion knock will occur, and that it will be particularly damaging because the charge density is so high. This phenomenon occurs as a result of abnormal combustion in the cylinder and presents a major limit to the performance of the engine. In extreme cases, knock can lead to catastrophic failure of engine component. The thermal stresses induced at the surface of the cylinder 
are proportional to the temperature gradients, which are directly related to the instantaneous heat flux. For this reason, further research into quantifying the effect of knock on in-cylinder heat transfer is of great importance to many engine manufacturers, and it is also necessary to relate the change in heat flux to knock parameters that are based on in-cylinder pressure measurements.

\section{Previous Research Relating Knock Intensity and Heat Flux}

Several researchers have sought correlations between surface heat flux and knock intensity [2, 3, 4]. Grandin and Denbratt [5] conducted their research on a single cylinder optical engine and concluded that knock intensities above $0.2 \mathrm{MPa}$ influenced the heat flux and above 0.6 MPa the peak heat flux was 2.5 times higher than for a non-knocking cycle. They suggest that this is due to the increased charge motion and subsequent increase in Reynolds number, as a result of auto-ignition. However, they did not define their knock index and there are limited details of the heat flux probe that was used. Figure 1 shows a plot of their surface temperature, cylinder pressure and heat flux. Their temperature plots are very 'smooth', so it is possible that there is too much filtering/smoothing, or the transducer time constant is too long.

Syrimis et al. [4] also found that under light knocking conditions, the ensemble-averaged peak heat flux was increased for locations near the end gas, and for heavy knock, the ensemble-averaged peak heat flux increased significantly throughout the piston crown. The pressure data were filtered to $3 \mathrm{kHz}$ and then analysed using a net heat release analysis, which is shown in Figure 2. A spike at about $20^{\circ}$ aTDC is attributed to auto-ignition, but this is somewhat later than is usually encountered; one possibility is that their digital filter has introduced a phase lag. Syrimis et al. sought to find correlations between the peak heat flux and various knock parameters. The results in Figure 3 are the most promising, but do not show any strong evidence of a correlation between the heat flux and knock intensity.

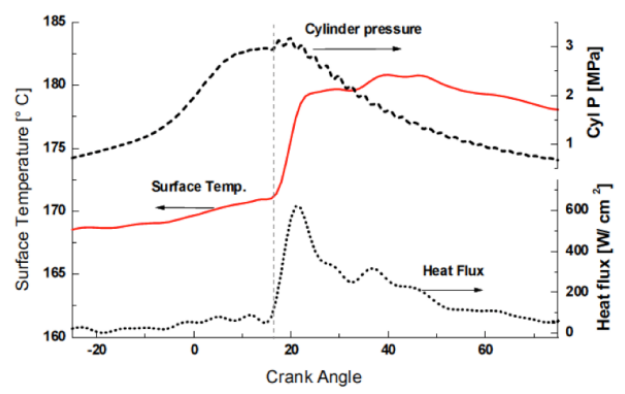

Figure 1 Data from Gradin and Denbratt [5] that appears to have been smoothed

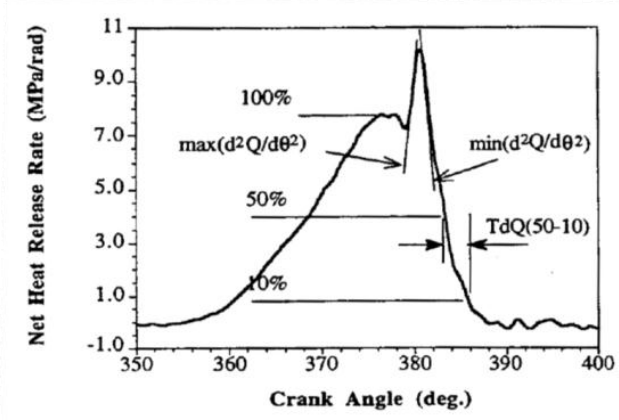

Figure 2 Results from Syrimis et al. [4] in which the knock event ( $\left.380^{\circ} \mathrm{ca}\right)$ is late, possibly a consequence of filtering the pressure data to $3 \mathrm{kHz}$, which might have introduced a phase lag 
Correlations have been reported on an averaged basis between the heat flux and the knock intensity, and since it is known that there will be spatial variations in the pressure history within the combustion chamber, then to obtain comparisons on a cycle-by-cycle basis it will be important to co-locate the pressure transducer and heat flux sensor. Comparisons on a cycle-by-cycle basis will be seen to be important as there appears to be a threshold of knock intensity above which there is a rapid increase in heat flux. This also raises the question of how to define the knock intensity and the corresponding change in the heat flux, and this is discussed after describing the experimental equipment.

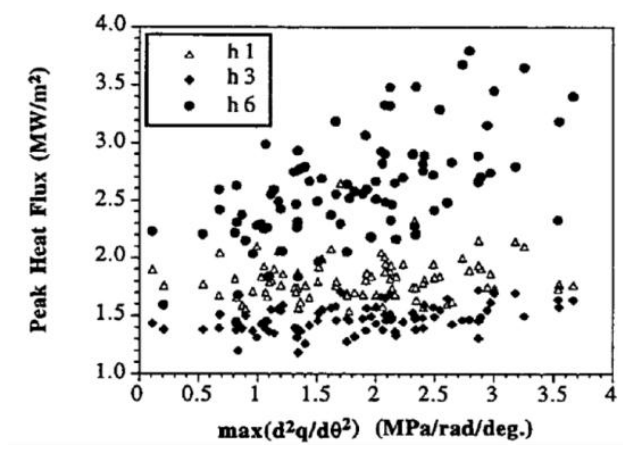

Figure 3 A scatter plot from Syrimis et al. [4] that records the heat flux at 3 different locations (h1, h3, h6)

\section{Experimental Equipment}

Most of the experiments were conducted using a Ricardo E6 variable compression ratio engine, which has the same disc-shaped combustion chamber as the Cooperative Fuel Research engine. Some additional tests were conducted with a Smart Car engine, as this has a contemporary 2-valve combustion system. The engine specifications are in Table 1.

Table 1 Engine Specifications

\begin{tabular}{|l|l|l|}
\hline & Ricardo E6 & Smart Car \\
\hline Engine Type & Single Cylinder, Naturally Aspirated & Three Cylinder, turbocharged \\
\hline Fuel Injection Type & Port fuel injection & Port fuel injection \\
\hline Bore & $76.2 \mathrm{~mm}$ & $66.5 \mathrm{~mm}$ \\
\hline Stroke & $111.1 \mathrm{~mm}$ & $67.0 \mathrm{~mm}$ \\
\hline Swept Volume & $507 \mathrm{~cm}^{3}$ & $698 \mathrm{~cm}^{3}$ \\
\hline Compression Ratio & $4.5-20$ & 9 \\
\hline
\end{tabular}


The Ricardo E6 engine was equipped with 3 fuel tanks, so that operation could be readily switched between different fuels. Engine speed was regulated by the dynamometers, and both engines had lambda sensors for controlling the air fuel ratio. The Smart Car engine relied on its thermostat to regulate the coolant temperature, while the Ricardo E6 had closed loop control of both the coolant (at $80^{\circ} \mathrm{C}$ ) and inlet air temperature $\left(\right.$ at $30^{\circ} \mathrm{C}$ ). Both engines were operated at $1000 \mathrm{rpm}$, with additional testing of the Smart Car engine at $2000 \mathrm{rpm}$.

Four different mixtures of iso-octane, n-heptane and toluene were tested, along with an unleaded gasoline (ULG). The composition of the fuel blends is given in Table 2, and the Research Octane Number (RON) and Motor Octane Number (MON) values are taken from the work by Smallbone et al. [6]. The properties of the ULG are given in Table 3, and this was the only fuel used in the Smart Car engine.

Table 2 Composition of the fuel blends (volume \%)

\begin{tabular}{|l|l|l|l|l|l|}
\hline $\begin{array}{l}\text { Fue } \\
\mathbf{l}\end{array}$ & $\begin{array}{l}\text { iso- } \\
\text { octan } \\
\text { e }\end{array}$ & $\begin{array}{l}\text { n- } \\
\text { hepta } \\
\text { ne }\end{array}$ & toluene & $\begin{array}{l}\text { RO } \\
\text { N }\end{array}$ & MON \\
\hline $\mathbf{1}$ & 100 & 0 & 0 & 100 & 100 \\
\hline $\mathbf{2}$ & 92 & 8 & 0 & 92 & 92 \\
\hline $\mathbf{3}$ & 20 & 20 & 60 & 92 & 80 \\
\hline $\mathbf{4}$ & 80 & 20 & 0 & 80 & 80 \\
\hline
\end{tabular}

Table 3 properties of the unleaded gasoline (ULG)

\begin{tabular}{|l|l|}
\hline RON & 97.0 \\
\hline MON & 87.7 \\
\hline Density @ 15 C & $0.744 \mathrm{~kg} / \mathrm{L}$ \\
\hline DVPE @ 37.8 $\mathrm{C}$ & $60.0 \mathrm{kPa}$ \\
\hline Aromatics \% v/v & 29.0 \\
\hline Olefins \% v/v & 1.8 \\
\hline Saturates \% v/v & 69.2 \\
\hline
\end{tabular}

The cylinder pressure was measured by a flush-mounted Kistler 6051A piezo-electric pressure transducer and charge amplifier that were calibrated as a pair; Figure 4. The pressure data, a reference flag and the surface temperature measurement from the heat flux probe were sampled at 100 ksamples/s with 12 bit resolution. 


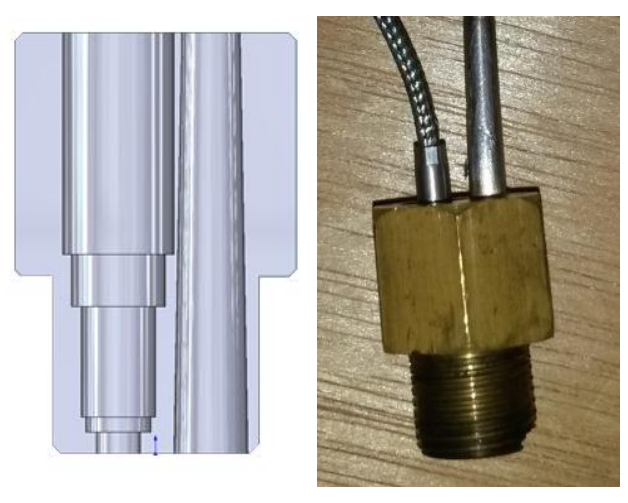

Figure 4 M14x1.25 adaptor for holding the pressure transducer and the heat flux probe (in the tapered hole).

The heat flux probe was of the Nanmac eroding thermocouple type which had a reference thermocouple junction $4.76 \mathrm{~mm}$ from the surface thermocouple. This is sufficiently far from the surface for the temperature to be steady. Figure 5 shows how the thermocouple ribbons are separated by an extremely thin sheet of mica insulation. The 'hot' measuring junction is formed by abrading the exposed ends of the thermocouple. The dielectric insulation between the Chromel and Alumel elements is so thin that in the process of eroding the surface, metallic 'whiskers' bridge the gap and form a junction [7].

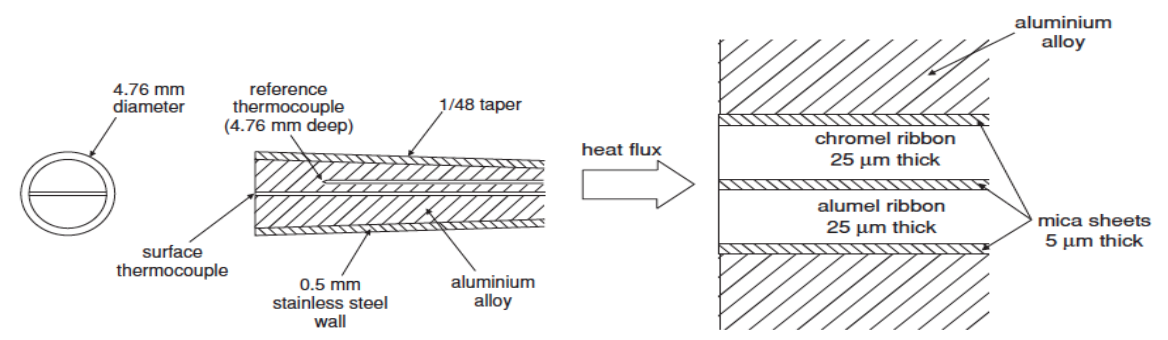

Figure 5 Construction of the heat flux probe with a surface thermocouple and a reference junction, and a detailed view of the surface thermocouple construction

To avoid the need for cold junction compensation, it was the difference between the surface and reference temperatures that were amplified. As the thermocouple output is only about $40 \mu \mathrm{V} / \mathrm{K}$, a high gain instrumentation amplifier had to be used. The surface temperature fluctuations were as much as $80 \mathrm{~K}$ during heavy knock, and this is in contrast to normal combustion for which the surface temperature fluctuations would be less than about $10 \mathrm{~K}$. The Ricardo E6 engine used a LabVIEW system for control and low speed data acquisition, while the Smart Car Engine used the Sierra CP Cadet system. In both cases the high speed data (100 ksample/s) was recorded using LabVIEW and then analysed in code written with MATLAB.

\section{Data Analysis}

The unsteady heat flow equation is a partial differential equation that can be expressed in finite difference form by using Taylor expansions. The finite difference equations were solved using an explicit formulation, with boundary conditions from the experimental data. The cylinder surface temperature data provides the surface boundary condition, and the reference temperature provides the other boundary condition. Data from a cycle is read into the code, the reference temperature is held constant and the initial temperature distribution between the boundaries is assumed to be linear. At each iteration, a new temperature distribution is found using the solution from the last step. This process continues by looping through the data from an individual cycle until the difference between two consecutive iterations is below $0.005 \mathrm{~K}$, at which point the solution has converged. For all subsequent cycles the initial temperature distribution is that at the end of the previous cycle. The thermal properties of Alumel were used, as this was the recommendation of Wang et al [7] when a 1D unsteady solution 
is being used. The code was validated by assuming a sinusoidal temperature variation, for which the analytical solution could be used for comparison.

Figure 6 shows the solution for the temperature distribution at a representative operating point.

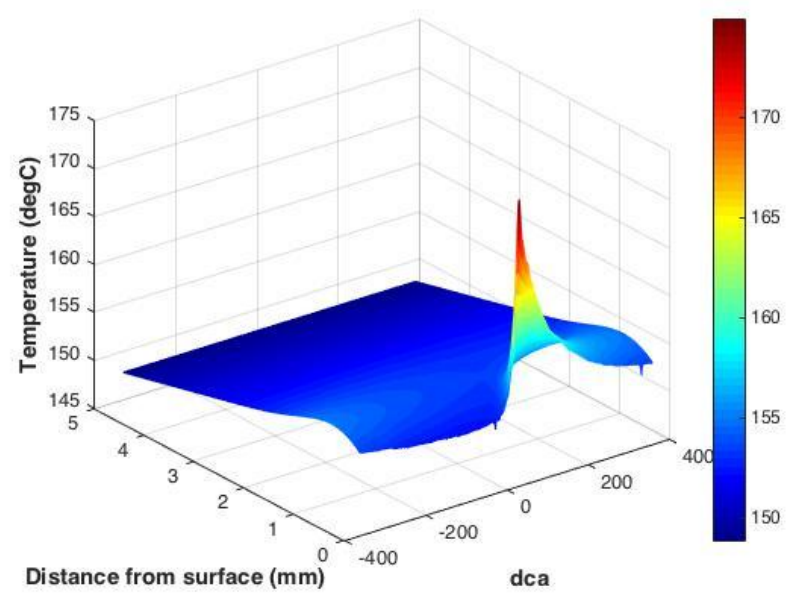

Figure 6 Temperature distribution between surface and reference thermocouples for one cycle using iso-octane at $1000 \mathrm{rpm}, \boldsymbol{\lambda}=1$, a compression ratio of 8 and ignition timing of $28^{\circ} \mathrm{bTDC}$

The surface temperature increases very quickly slightly after TDC as the flame front reaches the cylinder wall. The variation in temperature also damps out within 1.5-2 $\mathrm{mm}$ of the surface. Once the temperature distribution is known, the heat flux can then be calculated from the temperature gradient at the surface, and Figure 7 shows results from 20 consecutive cycles; because of the cycle-by-cycle variation about 100 cycles were sampled.

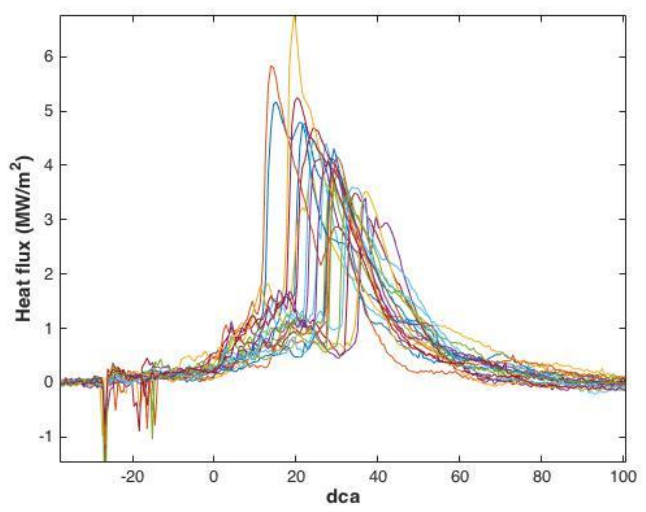

Figure 7 Plot of the surface heat flux for 20 consecutive cycles using iso-octane at $1000 \mathrm{rpm}, \lambda=1$, WOT, a compression ratio of 8 and ignition $28^{\circ} \mathrm{bTDC}$. Interference from the spark at the start $\left(28^{\circ} \mathrm{bTDC}\right)$ and end $\left(\sim 18^{\circ} \mathrm{bTDC}\right)$ has to be rejected.

There are many methods for detecting knock, both directly and indirectly, but in combustion research the most common method is in-cylinder pressure measurements. Although it provides the most direct method of knock measurement and has been extensively used [8], there is no single indicator of knock intensity that is universally accepted. However, there are commonly used pressure-based knock indices, and most of these use high-pass or 
band-pass filtered data so as to process the fluctuating components that are typically above $5 \mathrm{kHz}$. A selection of knock intensity parameters is listed next.

\section{Maximum Amplitude of Pressure Oscillations (MAPO)}

This is a very popular indicator of knock intensity due to its simplicity. It simply takes the maximum amplitude of the band-pass filtered pressure signal over the window of interest.

$$
M A P O=\max \left(|\bar{p}|_{\theta_{0}}^{\theta_{0}+W}\right)
$$

where $\overline{\boldsymbol{p}}$ is the bandpass filtered pressure signal

$\boldsymbol{\theta}_{\mathbf{0}}$ is the crank angle at the beginning of the knock window

$\mathbf{W}$ is the duration of knock window

\section{Integral of the Modulus of Pressure Oscillations (IMPO)}

This index sums the absolute values of the filtered pressure signal over the window of interest.

$$
I M P O=\sum_{\theta_{0}}^{\theta_{0}+W}|\bar{p}| d \theta
$$

\section{Logarithmic Knock Index (LKI)}

In contrast to the other two methods, this index uses the average energy of the filtered signal to describe knock intensity. This is appropriate given that the pressure oscillations are made up of many frequencies [10]. The average energy of a signal in the time domain is given by:

This is used to define the logarithmic knock index (LKI):

$$
\text { Average energy }=\frac{1}{N} \sum_{N=0}^{N-1} \bar{p}(k)^{2}
$$

$$
L K I=\ln \left[\frac{1}{W} \sum_{K=1}^{W} \bar{p}(k)^{2}\right]
$$

The size of the window over which the MAPO, IMPO and LKI are calculated is a matter of debate. Brunt et al. [9] suggest that a window from TDC to TDC+40 degrees crank angle should be adequate for most knock analysis, however a tighter window can be used if processing time and data storage are limited.

One method of assessing the robustness of these knock parameters is to down-sample data collected at a much higher sampling rate, and to compare the results from analyzing the down-sampled data with the original data, and to phase the start of the down-sampled data. Representative results are shown in Table 4.

Table 4 shows that the three methods (MAPO, IMPO, LKI) considered here appear to give equally good results, but there needs to be two notes of caution. Firstly, the results are an average of 100 cycles, and secondly the conclusions may not be valid at lower sampling rates. At a lower sampling rate different values of the Maximum Amplitude of Pressure Oscillations (MAPO) would be identified for a given cycle, and when the results are averaged out across many cycles variability in the MAPO will be masked. In the work here, which considers an individual cycle, the Integral of the Modulus of Pressure Oscillations (IMPO) and Logarithmic Knock Index (LKI) are preferred as they make more use of the information that is available and can be related to energy in the pressure fluctuations. 
Table 4 Down-sampled data for 100 cycles collected at $200 \mathrm{ksamples} / \mathrm{s}$ that is used to compare three pressurebased knock indices: Maximum Amplitude of Pressure Oscillations (MAPO), Integral of the Modulus of Pressure Oscillations (IMPO) and Logarithmic Knock Index (LKI)

\begin{tabular}{|c|c|c|c|c|c|}
\hline \multirow[b]{2}{*}{$\begin{array}{l}\text { Knock } \\
\text { Index }\end{array}$} & \multirow{2}{*}{$\begin{array}{l}\text { (Not } \\
\text { Down- } \\
\text { sampled) }\end{array}$} & \multicolumn{4}{|c|}{ Down-sampled Data } \\
\hline & & $1,5,9 \ldots$ & $2,6,10$. & $3,7,11$. & $4,8,12 \ldots$ \\
\hline MAPO & 1.38 & 1.35 & 1.39 & 1.39 & 1.38 \\
\hline IMPO & 4.99 & 5.10 & 5.08 & 5.08 & 5.10 \\
\hline LKI & -3.19 & -3.09 & -3.10 & -3.09 & -3.07 \\
\hline
\end{tabular}

\section{Results}

\section{Cycle-by-Cycle Results}

Due to the close proximity of the pressure transducer and the thermocouple, the surface temperature should accurately reflect how the knock intensity affects the instantaneous heat flux on a cycle-by-cycle basis. For all three fuels, it was found that there was very little relationship between the peak heat flux and knock intensity under very light knocking conditions. Figure 8 shows scatter plots of the peak heat flux $\left(Q_{\max }\right)$ against the MAPO, IMPO and LKI for Fuel 2.
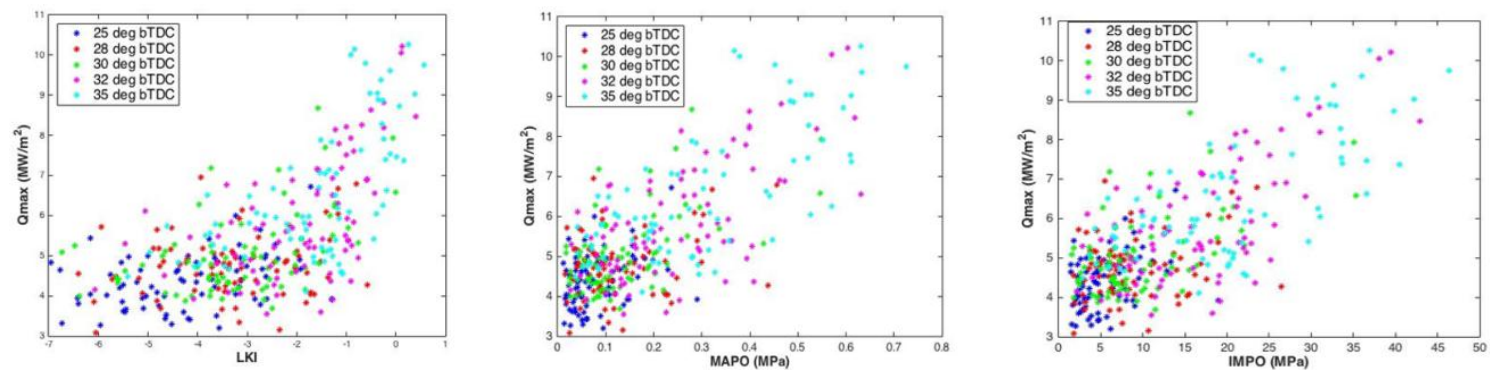

Figure 8 Scatter plots of $\boldsymbol{Q}_{\max }$ against LKI, MAPO and IMPO for 86 consecutive cycles using Fuel 2 for $\lambda=0.9$, a compression ratio of 7 and a range of ignition timings in the Ricardo E6 engine. 
It can be seen from the plots of $Q_{\max }$ against MAPO and IMPO, that at ignition timings of $25^{\circ} \mathrm{bTDC}$ to $30^{\circ} \mathrm{bTDC}$, there is very little correlation between the peak heat flux and knock intensity. However, for the more advanced ignition timings, $Q_{\max }$ increases almost linearly with knock intensity. The plot of $Q_{\max }$ against LKI shows that for cycles with an LKI of less than -1 , knock intensity appears to have little effect on the peak heat flux. However, above this value, the correlation between $Q_{\max }$ and LKI becomes much stronger, as will be seen in Figure 10.
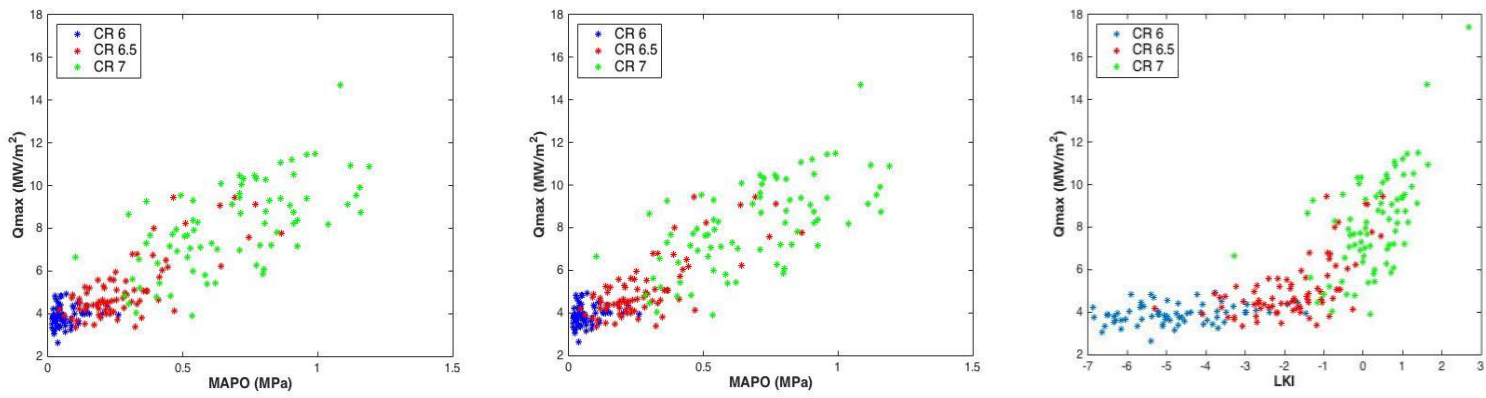

Figure 9 Scatter plots of peak heat flux against LKI, MAPO and IMPO for 87 consecutive cycles using Fuel 3 at $30^{\circ} \mathbf{b T D C}$ and $\lambda=\mathbf{1}$ for compression ratios of 6, 6.5 and 7 in the Ricardo E6 engine.

Figure 9 compares $Q_{\max }$ with MAPO, IMPO and LKI using Fuel 3 for compression ratios of 6, 6.5 and 7 at $30^{\circ}$ bTDC and a stoichiometric $(\lambda=1)$ mixture. The progression from very light knock to heavy knock was well defined, which is reflected in the average values of LKI, which were $-5.72,-1.78$ and 0.26 respectively. From all three plots it can be seen that there is little relationship between the peak heat flux and knock intensity for very light knock at a compression ratio of 6 . For some cycles at a compression ratio of 6.5, knock had an effect on $Q_{\max }$. However, for a compression ratio of 7, the plots of $Q_{\max }$ against MAPO and IMPO show a stronger correlation between $Q_{\max }$ and knock intensity. Similarly with the plot of $Q_{\max }$ against LKI, there is a clear progression for each compression ratio, with the strongest relationship at an LKI of above -1 .

An alternative to using the peak heat flux is to integrate the heat flux over a time window of 60 degrees either side of top dead centre When the same data reported in Figure 9 is analysed this way the results (Figure 10) show broadly the same tends, once allowance is made for the different ordinate.
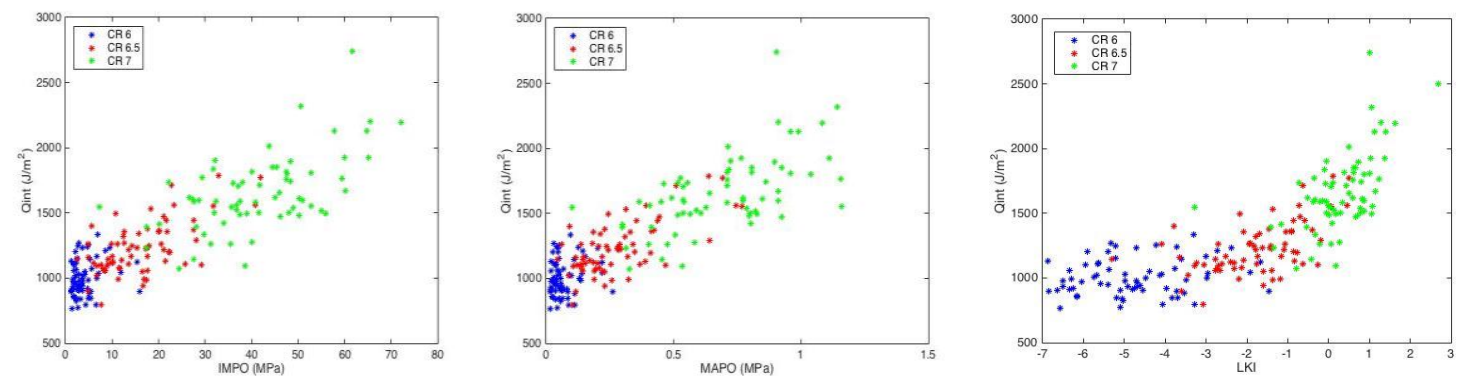

Figure 10 Scatter plots of integrated heat flux against LKI, MAPO and IMPO for 87 consecutive cycles using Fuel 3 at $30^{\circ} \mathbf{b T D C}$ and $\lambda=\mathbf{1}$ for compression ratios of 6, 6.5 and 7 in the Ricardo E6 engine.

Plots of the angle of occurrence of the peak heat flux against the knock parameters showed the expected trends namely the more intense the knock the earlier the angle at which the peak heat flux occurs. 


\section{Smart Car engine data}

The Smart Car engine has a squish region, so is very unlike the simple disc shaped combustion chamber of the Ricardo E6. The squish region generates significant turbulence, such that the burn rate in the Smart Car engine will be about double that of the Ricardo E6 engine.
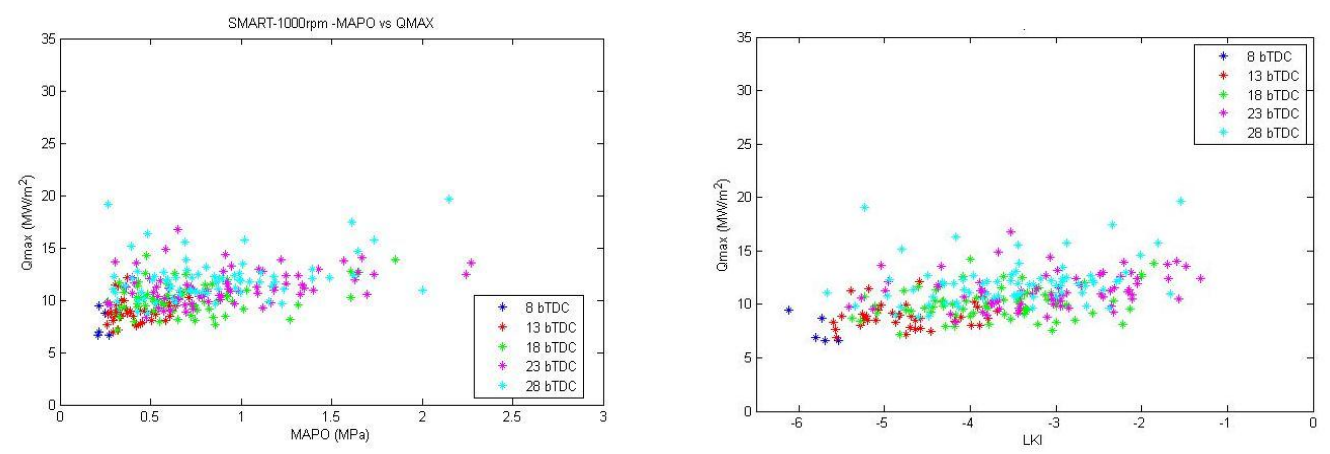

Figure 11 Scatter plots of peak heat flux against MAPO and LKI for 87 consecutive cycles using unleaded gasoline at $\boldsymbol{\lambda}=\mathbf{1}$ for changing ignition timing in the Smart Car engine at $1000 \mathrm{rpm}$.

Figure 11 shows a scatter plot of the peak heat flux against MAPO and LKI for 87 consecutive cycles using unleaded gasoline at $\lambda=1$ for a range of ignition timings in the Smart Car engine at $1000 \mathrm{rpm}$. Compared with Figure 8 for the Ricardo E6 engine, the heat flux is about twice as high for a given value of LKI, and this can be explained by there being a higher level of turbulence that increases the burn rate, and the higher compression ratio leading to higher in-cylinder pressures. Similar results were found at $2000 \mathrm{rpm}$ except that there was more scatter in the data and the trend-line was about $30 \%$ higher; this can be explained by there being a higher level of turbulence. The MAPO data showed a similar difference for the two engine speeds. At both speeds concerns over the increased levels of heat flux during knocking combustion limited the extent of the ignition advance compared with the test in the Ricardo E6. 

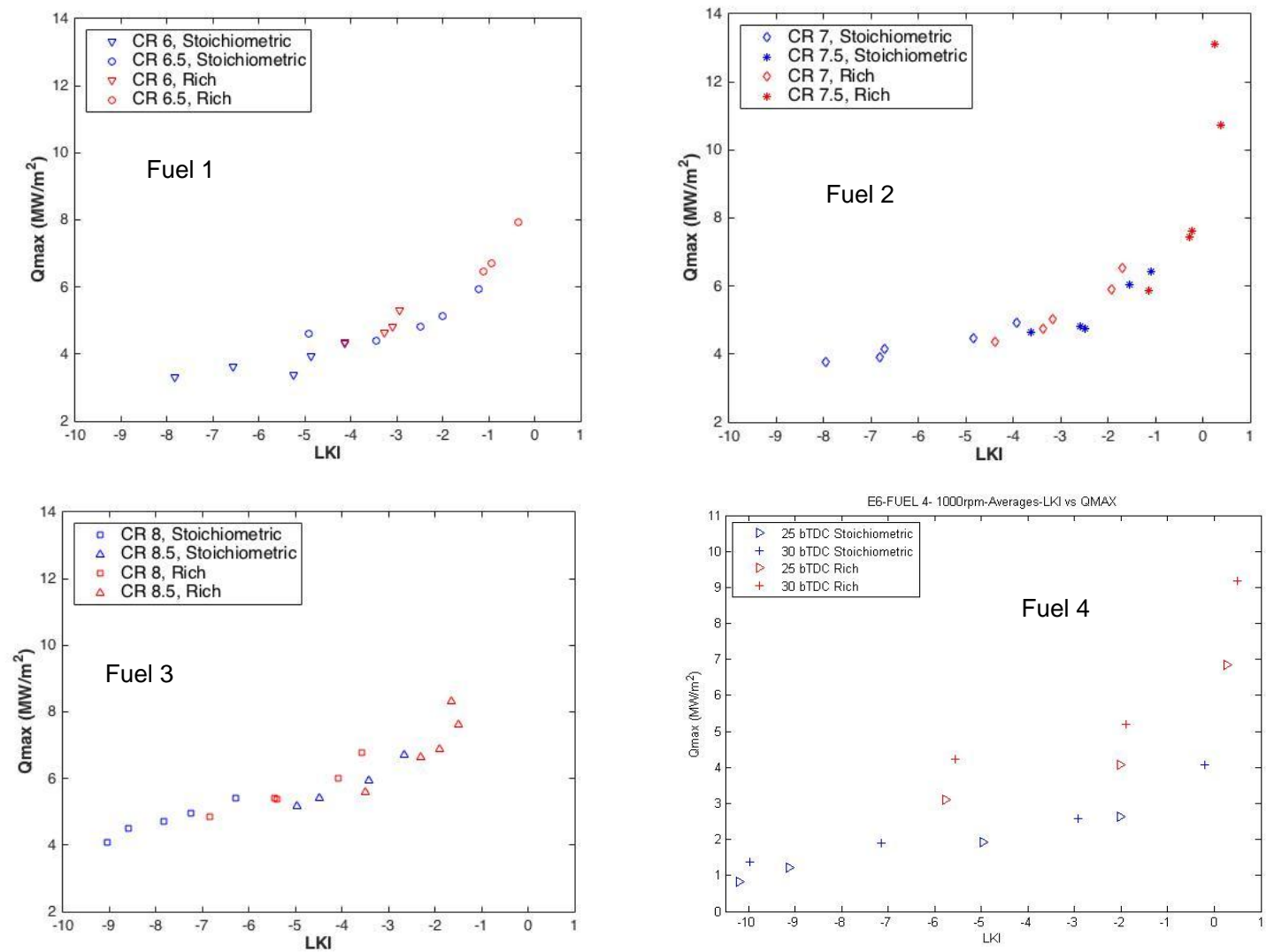

Figure 12 Scatter plots of the average peak heat flux against LKI for a range of ignition timings from $25^{\circ} \mathrm{bTDC}$ to $35^{\circ} \mathrm{bTDC}$ (but $25^{\circ} \mathrm{bTDC}$ and $30^{\circ} \mathrm{bTDC}$ for Fuel 4 )and varying compression ratios and mixture strengths $(\lambda=1, \lambda=0.9)$ for all four fuels.

As would be expected, the cycle averaged results show the same trends, and it is possible to show data from a wider range of test conditions on a single plot. However, mean values might not be an entirely useful parameter for predicting potential damage, as thermal fatigue might be disproportionately affected by the highest values of the peak heat flux.

Figure 12 shows scatter plots of the average peak heat flux against LKI for a range of ignition timings from $25^{\circ} \mathrm{bTDC}$ to $35^{\circ} \mathrm{bTDC}$ and varying compression ratios and mixture strengths. For Fuels 1-3 in each dataset, the data points refer to ignition timings $25^{\circ} \mathrm{bTDC}$ to $35^{\circ} \mathrm{bTDC}$ sequentially from left to right, as advancing the spark timing increased the knock intensity. Fuel 4 was tested at lower compression ratios and a reduced range of ignition timings because of the lower octane rating $(\mathrm{RON}=\mathrm{MON}=80)$. The lower compression ratio led to lower in-cylinder pressures and this accounts for the generally lower values of heat flux.

As with the cycle-by-cycle results, there is a marked increase in the heat flux once the LKI is above -1 . The results from Fuels 1-3 would collapse onto a single plot, while the results from Fuel 4 (with RON $=$ MON $=80$ ) are lower, and this shows that the correlation between the knock intensity and peak heat flux is not independent of the fuel, compression ratio, ignition timing and mixture strength

The corresponding results for the maximum amplitude of pressure oscillation (MAPO) are very similar, and the MAPO results from Fuels 1-3 of Figure 12 are combined and plotted here in Figure 13. 


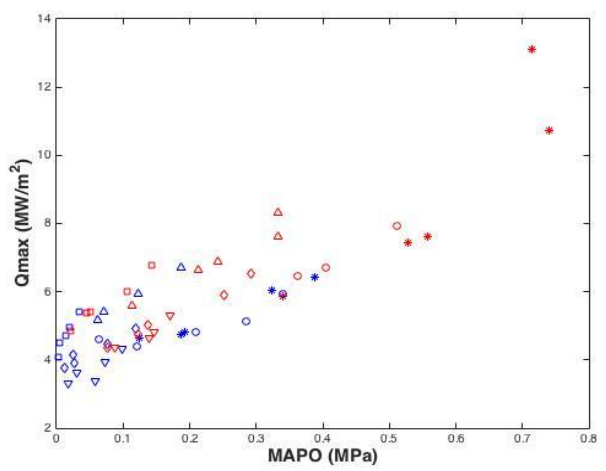

Figure 13 Scatter plot of the average peak heat flux and the against maximum amplitude of pressure oscillation (MAPO) for Fuels 1-3 with a range of ignition timings from $25^{\circ} \mathrm{bTDC}$ to $35^{\circ} \mathrm{bTDC}$ and varying compression ratios and mixture strengths $(\boldsymbol{\lambda}=\mathbf{1}, \boldsymbol{\lambda}=0.9)$.

The corresponding plot to Figure 12 for the Smart Car engine is Figure 14, and that corresponding to Figure 13 is Figure 15. Figure 14 shows a scatter plot of the average peak heat flux against LKI for 87 consecutive cycles using unleaded gasoline at $\lambda=1$ for changing ignition timing in the Smart Car engine at $1000 \mathrm{rpm}$. Compared with the results in the Ricardo E6 engine, the heat flux in Figure 14 is about double for a given LKI, and this is attributed to the higher compression ratio and higher level of in-cylinder turbulence. For the MAPO plotted in Figure 15, at a given value of MAPO the peak heat flux is about 30\% higher in the Smart Car engine than in the Ricardo E6 (Figure 13).

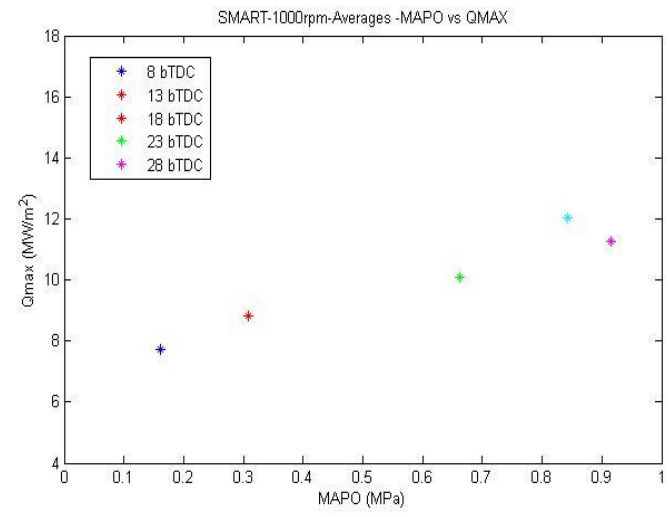

Figure 14 Scatter plot of the average peak heat flux against LKI for 87 consecutive cycles using unleaded gasoline at $\lambda=1$ for changing ignition timing in the Smart Car engine at $1000 \mathrm{rpm}$.

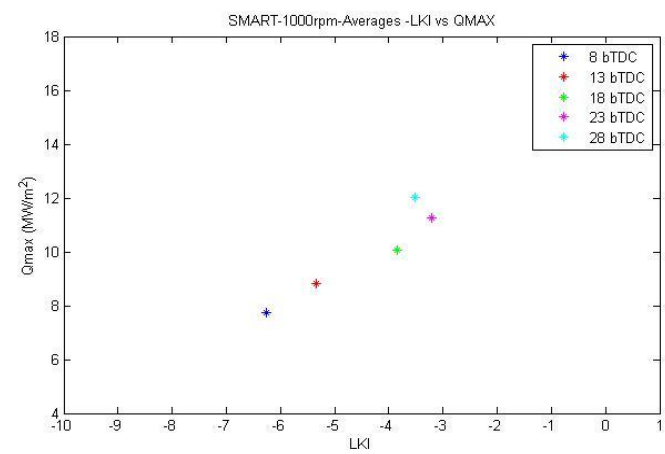

Figure 15 Scatter plots of the average peak heat flux against MAPO for 87 consecutive cycles using unleaded gasoline at $\lambda=1$ for changing ignition timing in the Smart Car engine at $1000 \mathrm{rpm}$. 
The question might be asked - is it necessary to measure the heat flux, or would it have been sufficient to measure a steady metal temperature. This question is answered by Figure 16 which uses data from Fuel 2. In Figure 16 the greater scatter in the results for the reference temperature compared with the $Q_{\max }$ when plotted against the maximum amplitude of pressure oscillation (MAPO) indicate that the reference temperature is less useful than pressure or heat flux measurements.
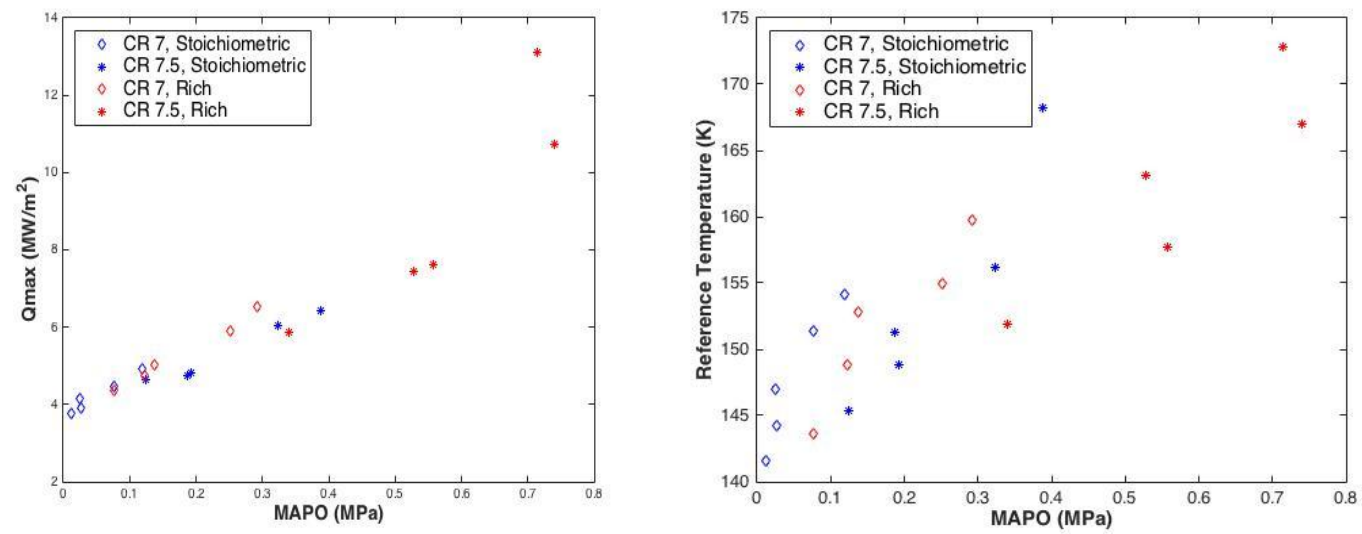

Figure 16 Scatter plot of the (a) average peak heat flux and (b) Reference Temperature against maximum amplitude of pressure oscillation (MAPO) for Fuel 2 I the Ricardo E6, with a range of ignition timings from $25^{\circ} \mathrm{bTDC}$ to $35^{\circ} \mathrm{bTDC}$ and varying compression ratios and mixture strengths $(\boldsymbol{\lambda}=\mathbf{1}, \boldsymbol{\lambda}=0.9)$.

\section{Conclusions}

The aim of this project was to investigate the effect that combustion knock has on the instantaneous heat flux at the surface of the combustion chamber in a spark ignition engine. A pressure transducer and eroding-type thermocouple were placed close together (with their centres $6 \mathrm{~mm}$ apart) in the end-gas region to measure the in-cylinder pressure and surface temperature during knocking combustion. The heat flux was calculated from the surface temperature data using a one-dimensional finite difference method in MATLAB. This procedure was checked with an analytical solution before it was used with experimental results. Well known knock indices such as the Maximum Amplitude of Pressure Oscillations (MAPO), Integral of the Magnitude of Pressure Oscillations (IMPO) and Logarithmic Knock Index (LKI) were defined and used as references to investigate the effect that knock had on the surface heat flux. Three knock intensity parameters were evaluated from the heat flux data: the peak heat flux $\left(Q_{\max }\right)$, the integral of heat flux over a given window $\left(Q_{\text {int }}\right)$ and the crank angle at which peak heat flux occurs $\left(Q_{\text {ang }}\right)$. These were compared with the reference knock indices on a cycle-by-cycle and cycle-averaged basis. The in-cylinder pressure and surface temperature were recorded for a range of compression ratios, ignition timings and air-fuel ratios in the Ricardo E6 engine, using four fuels with different octane ratings. Fuel 2 and Fuel 3 were more prone to knock than Fuel 1 as expected with a RON of 92 . However, as Fuel 3 had a MON of 80 (compared with 92 for Fuel 2) it was the less resistant to knock, but still better than Fuel $4(\mathrm{RON}=\mathrm{MON}=80)$. The key findings from the cycle resolved measurements in the Ricardo E6 engine are:

- For all four fuels, it was found that there was less correlation between the instantaneous surface heat flux and knock intensity under very light knocking conditions on a cycle-by cycle basis.

- The knock intensity was increased by advancing the ignition timing, increasing the compression ratio, using a lower octane rating fuel or using a richer mixture. Under heavier knocking conditions the correlation between heat flux and knock intensity became stronger for all four fuels.

- $\quad$ For values of LKI above approximately $-1, Q_{\max }$ and $Q_{\text {int }}$ increased almost linearly with LKI.

- The crank angle at which peak heat flux occurred was found to decrease as knock intensity increased. 
Similar relationships were reflected in the analysis of the cycle-averaged results and the relationship between peak heat flux and knock intensity was largely independent of the conditions in the Ricardo E6 engine used to achieve a given knock intensity.

The tests with the Smart Car engine showed that as the speed was increased from 1000 to $2000 \mathrm{rpm}$, then there was a significant increase in the maximum heat flux for fixed values of either MAPO (30\% higher peak heat flux) or LKI (approximately double the peak heat flux). The increase in heat flux can be accounted for by an increase in the turbulence intensity. The intrinsically higher level of turbulence from squish in the Smart Car engine (compared with the Ricardo E6 engine), along with the higher compression ratio, accounts for the higher values of heat flux at $1000 \mathrm{rpm}$ in the Smart Car engine.

The knocking combustion disrupts the boundary layer at the surface of the combustion chamber, but the mechanism by which the pressure oscillations from knocking cycles affect the thermal boundary layer remains unclear. It is a very complex area as the flows are highly unsteady, turbulent and compressible. It would be interesting work for future projects to investigate how the boundary layer is influenced under light and heavy knocking conditions. As automotive companies continue to downsize engines, knock is a major concern not only as a barrier to performance and efficiency but also due to the fact that knocking cycles are more severe under the conditions in highly boosted engines. Therefore, it would be useful to investigate the instantaneous heat flux under conditions that would cause component failure. The reference temperature just below the surface was found to increase at a higher rate under heavy knocking conditions. Measuring a single temperature of the cylinder to assess potential damage to the engine would be much simpler than evaluating the instantaneous heat flux, but the correlation was poor between this metal temperature and the knock intensity. Furthermore, it is the differential thermal strain that leads to thermal stresses and these will depend on the temperature gradient, which is directly related to the instantaneous heat flux.

\section{References}

1. http://www.bosch.com

2. Lu, J.-H., Ezekoye, D., Iiyama, A., Greif, R. and Sawyer, R. F., "Effect of Knock on Time-Resolved Engine Heat Transfer", SAE Paper 890158, 1989.

3. Harigaya, Y., Toda, F., Ohyagi, S. and Tsuji, H., "Surface Temperature and Wall Heat Flux in a Spark Ignition Engine under Knocking and Non-Knocking Conditions", SAE Paper 891795.

4. Syrimis, M.,Shigahara, K. and Assanis, D., "Correlation Between Knock Intensity and Heat Transfer Under Light and Heavy Knocking Conditions in Spark Ignition Engines", SAE Paper 960495

5. Grandin, B. and Denbratt, I., "The Effect of Knock on Heat Transfer in SI Engines", SAE Paper 2002-010238 .

6. Smallbone, A. J., Morgan, N., Bhave, A., Kraft, M., Cracknell, R., F. and Kalghatgi, G., "Simulating Combustion of Practical Fuels and Blends for Modern Engine Applications Using Detailed Chemical Kinetics", SAE Paper 2010-01-0572, 2010

7. Xiaowei Wang, Richard Stone, David Buttsworth, Robert Stevens and Yoshi Arita "Finite Element Analysis of Eroding Type Surface Thermocouple with Application to Engine Heat Flux Measurement", SAE Paper 2006-01-1045. Also in SP-2015 Combustion and Flow Diagnostics and Fundamental Advances in Thermal Fluid Sciences.2006.

8. X. Zhen, Y. Wang, S. Xu, Y. Zhu, C. Tao, T. Xu and M.Song. "The engine knock analysis - An overview". Applied Energy Vol 92, Pages 628-636, 2012.

9. Brunt, M. F. J., Pond, C. R. and Biundo, K., "Gasoline Engine Knock Analysis using Cylinder Pressure Data", SAE Paper 980896, 1998

10. Hudson, C., Gao, X. and Stone, C. R., "Knock measurement for fuel evaluation in spark ignition engines", Fuel, vol 80, pp. 395-407, 2001. 


\section{Appendix}

The unsteady heat equation is a partial differential equation, which can be solved numerically for a given set of boundary conditions and a known initial condition. The following analysis is for one-dimensional heat transfer, however this can be extended to higher dimensions.

$$
\frac{\partial T}{\partial t}=\alpha \frac{\partial^{2} T}{\partial x^{2}}
$$

where $=\frac{k}{\rho c}$, the thermal diffusivity

Using a Taylor expansion, the first and second derivatives from equation A.1 are approximated as shown below (note that these equations are shown in the time domain but apply equally to the space domain as used later):

$$
\begin{aligned}
& T(x, t)_{t+\Delta t} \approx T(x, t)_{t}+\Delta t T^{\prime}(x, t)+\frac{\Delta t^{2}}{2} T^{\prime \prime}(x, t) \\
& T(x, t)_{t-\Delta t} \approx T(x, t)_{t}-\Delta t T^{\prime}(x, t)+\frac{\Delta t^{2}}{2} T^{\prime \prime}(x, t)
\end{aligned}
$$

Equation A.2 is rearranged to give the forward difference approximation A.4, assuming the higher order $\Delta t$ terms are negligible. In the same way, the backward difference method can be obtained from equation A.3.

$$
\frac{\partial T}{\partial t} \approx \frac{T(x, t)_{t+\Delta t}-T(x, t)_{t}}{\Delta t}
$$

A central difference approximation is used for the second derivative in the space domain:

$$
\frac{\partial^{2} T}{\partial x^{2}} \approx \frac{T(x, t)_{x+\Delta x}-2 T(x, t)_{x}+T(x, t)_{x-\Delta x}}{\Delta x^{2}}
$$


These approximations are then substituted into equation A.1 to give:

$$
\frac{T(x, t)_{t+\Delta t}-T(x, t)_{t}}{\Delta t} \approx \alpha \frac{T(x, t)_{x+\Delta x}-2 T(x, t)_{x}+T(x, t)_{x-\Delta x}}{\Delta x^{2}}
$$

Finally, rearranging to solve for the temperature distribution at the new time step gives:

$$
T(x, t)_{t+\Delta t} \approx T(x, t)_{t}+r\left[T(x, t)_{x+\Delta x}-2 T(x, t)_{x}+T(x, t)_{x-\Delta x}\right]
$$

where $r=\frac{\alpha \Delta t}{\Delta x^{2}}$, the Fourier number

This method is an iterative process since at every time step $(\mathrm{t}+\Delta \mathrm{t})$, the temperature distribution is found by solving equation A.7 for each grid point using the values from the time step (t). This is an explicit formulation as only known values are used to calculate the new temperature distribution. The grid in Figure A.1 can be used to visualise what it is happening at each time step.

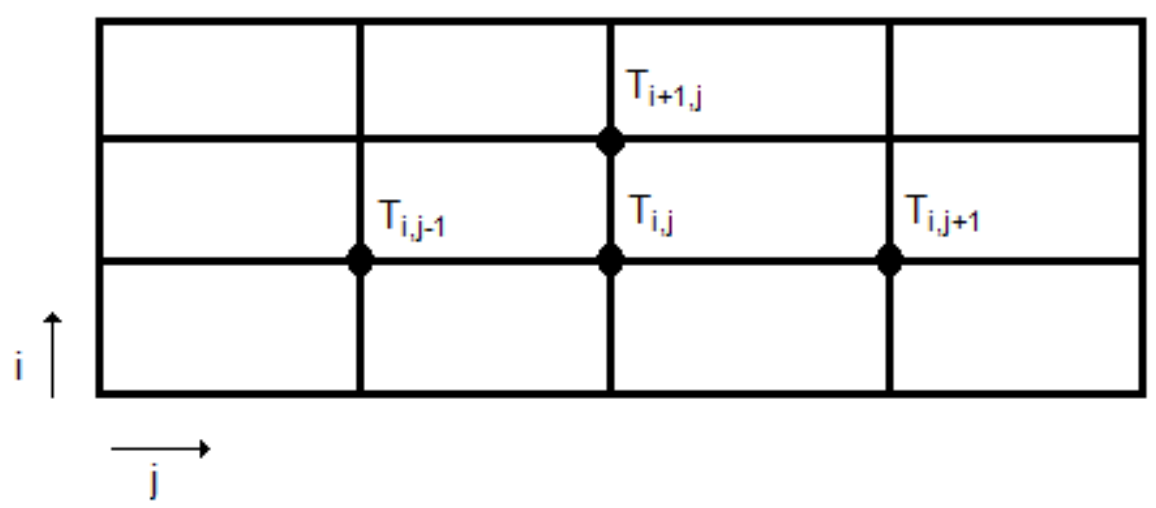

Figure A.1 Visualisation of the explicit finite difference method. The i direction represents the time steps and the $\mathbf{j}$ direction represents the spatial grid

Once the temperature distribution is found, the instantaneous heat flux is calculated using a discretized version of Fourier's law: 


$$
\dot{q}=k \frac{T_{s}-T_{1}}{\Delta x}
$$

Where $T_{S}$ is the surface temperature

$T_{1}$ is the temperature of the first grid element

$\Delta x$ is the grid step size

A disadvantage of using an explicit finite difference method is that there is a constraint on the size of the time step $\Delta t$ and grid spacing $\Delta x$ such that $r \leq 0.5$ for a stable solution ${ }^{[1]}$. For a given sampling rate and thermal diffusivity, an upper limit on the number of grid points, $N$, is given by:

$$
N=L \sqrt{\frac{r}{\alpha \Delta t}}
$$

where $L$ is the length between the surface and the reference point in metres.

Implicit methods, such as the Crank-Nicholson method, guarantee stability. However, they require the solution of several simultaneous equations at each time step and so are more complex and computationally costly.

[1] F. J. Bayley, A. B. Turner and J. M. Owen, "Heat Transfer”, Nelson, 1972 